Int. J. Dev. Biol. 58: 175-181 (2014)

doi: $10.1387 / \mathrm{ijdb} .140059 \mathrm{mr}$

\title{
Embryo-endometrial interactions during early development after embryonic diapause in the marsupial tammar wallaby
}

\author{
MARILYN B. RENFREE* and GEOFF SHAW \\ Department of Zoology, The University of Melbourne, Victoria, Australia
}

\begin{abstract}
The marsupial tammar wallaby has the longest period of embryonic diapause of any mammal. Reproduction in the tammar is seasonal, regulated by photoperiod and also lactation. Reactivation is triggered by falling daylength after the austral summer solstice in December. Young are born late January and commence a 9-10-month lactation. Females mate immediately after birth. The resulting conceptus develops over 6- 7 days to form a unilaminar blastocyst of 80-100 cells and enters lactationally, and later seasonally, controlled diapause. The proximate endocrine signal for reactivation is an increase in progesterone which alters uterine secretions. Since the diapausing blastocyst is surrounded by the zona and 2 other acellular coats, the mucoid layer and shell coat, the uterine signals that maintain or terminate diapause must involve soluble factors in the secretions rather than any direct cellular interaction between uterus and embryo. Our studies suggest involvement of a number of cytokines in the regulation of diapause in tammars. The endometrium secretes platelet activating factor (PAF) and leukaemia inhibitory factor, which increase after reactivation. Receptors for PAF are low on the blastocyst during diapause but are upregulated at reactivation. Conversely, there is endometrial expression of the muscle segment homeobox gene MSX2 throughout diapause, but it is rapidly downregulated at reactivation. These patterns are consistent with those observed in diapausing mice and mink after reactivation, despite the very different patterns of endocrine control of diapause in these 3 divergent species. These common patterns suggest a similar underlying mechanism for diapause, perhaps common to all mammals, but which is activated in only a few.
\end{abstract}

KEY WORDS: embryonic diapause, marsupial, MSX, PAF, LIF

\section{Introduction}

The ability to arrest embryonic development during the reproductive cycle is widespread amongst mammals (Lopes et al., 2004, Murphy, 2012, Renfree and Calaby, 1981, Renfree and Shaw, 2000). Embryonic diapause is a transient state in which embryos at the blastocyst stage are arrested in growth and metabolic activity in synchrony with uterine quiescence. There are a number of forms of this developmental arrest, but all lengthen the period of gestation. This allows selection for traits that regulate the timing of diapause so that birth of the neonate(s), or weaning in the case of marsupials, coincides with the most favourable time for survival (Renfree and Calaby, 1981, Renfree and Shaw, 2000). However, the mechanisms used to control diapause are variable amongst mammals.

Many marsupial species undergo embryonic diapause. Blastocysts may either cease cell division, as in most macropodid marsupials, so that their size and cell numbers remain constant (Renfree and Shaw, 2000), or undergo an early period of very slow growth with cell division and expansion, as in the nectarivorous honey possum (Renfree, 1981) and the feathertail glider (Ward and Renfree, 1988). The tammar wallaby, Macropus eugenii, is the best studied diapausing marsupial (Renfree and Shaw, 2000). However, whilst the lactational (from the sucking stimulus), photoperiodic (via melatonin) and endocrine (via progesterone) control of diapause is now well understood in the tammar (Tyndale-Biscoe and Renfree, 1987), the specific endometrial-embryo interactions that occur at and after reactivation and their molecular control are only just beginning to be understood. This review will focus on those interactions.

Abbreviations used in this paper: LIF, leukaemia inhibitory factor; MSX, muscle segment homeobox; PAF, platelet activating factor.

*Address correspondence to: Marilyn B. Renfree. Department of Zoology,The University of Melbourne, Victoria 3010 Australia. E-mail: m.renfree@ unimelb.edu.au 
Marsupials are unusual in that they have two completely separate uteri (not uterine horns), and in the macropodids (the kangaroos and wallabies), ovulation occurs from alternate ovaries, so that in any one pregnancy there is one gravid uterus and one non-gravid one. This affords the opportunity to have an "inbuilt" control for any changes that occur during the short pregnancy before they deliver their highly altricial young. In addition, since the oestrous cycle is shorter than the pregnancy (by around a day or two), the changes that occur during a normal oestrous cycle are continuing in the non-gravid uterus during the whole of the pregnancy (Tyndale-Biscoe and Renfree, 1987).

\section{Entry into and maintenance of diapause}

In diapausing mammals, the entry into diapause is controlled by signals including the suckling stimulus, the change in daylength or the availability of nutrition (see Flint et al., 1981). In the tammar wallaby Macropus eugenii, a small macropodid marsupial, the young are born towards the end of the pro-oestrous phase. In late gestation the maturing fetus produces increasing amounts of cortisol that may provide the fetal signal for parturition (Ingram et al., 1999, Shaw et al., 1996). At term, progesterone falls rapidly concomitantly with short pulses of prostaglandin F2 $\alpha$ and mesotocin (Parry et al., 1996, Renfree et al., 1994) that trigger uterine contractions and parturition (Shaw and Renfree, 2001, Shaw and Renfree, 2006). Mating occurs about $1 \mathrm{~h}$ post-partum (Rudd, 1994), and ovulation and fertilisation occur about $40 \mathrm{hrs}$ post-partum (Renfree, 1994, Renfree and Lewis, 1996). Transport down the oviduct takes under $24 \mathrm{~h}$, and during this passage the zona-enclosed zygote is further enclosed in a mucin layer derived from oviducal secretions, and a final layer, the shell coat laid down at the utero-tubal junction (Renfree and Lewis, 1996). Cleavage commences once the zygote reaches the uterus (Fig. 1). As with all marsupials, there is no morula stage, no compaction and no inner cell mass in the tammar embryo (McLaren, 1982, Renfree and Lewis, 1996). The formation of the unilaminar blastocyst is complete by about day 7-8 post-coitum (Tyndale-Biscoe, 1979). At this stage, if the female is suckling a young, or is in the non-breeding season, the embryo will enter diapause, remaining dormant until reactivated by the termination of lactation before the winter solstice or the end of the non-breeding season in December at the summer solstice. The tammar diapausing blastocyst is remarkably uniform, consisting of a single layer of approximately $80-100$ cells (Fig. 1) (Renfree and Tyndale-Biscoe, 1973, Smith, 1981). If there is no sucking young in the pouch, pregnancy proceeds uninterrupted, and by day 19 of the 26.5 day gestation, embryogenesis is completed, organogenesis is initiated, the shell coat breaks down and the embryo attaches to the endometrium (Denker and Tyndale-Biscoe, 1986, Renfree, 1973b, Renfree, 1994, Renfree and Tyndale-Biscoe, 1973).

The endocrinology underlying lactational and seasonal diapause is well understood, but the precise details of the molecular changes that occur in the uterus and blastocyst are not known (Renfree, 2000). Few studies have investigated the influence of the ovarian hormones on uterine secretions from the time of ovulation to the formation of the early blastocyst. At oestrus, there is a surge of oestrogen peaking 1-2 days after birth that precedes the ovulation (Shaw and Renfree, 1984). Oestrogen then remains low for the period of embryonic diapause in the tammar. After ovulation, the corpus luteum forms slowly. If there is a newborn young in the pouch the pituitary releases prolactin as a result of the sucking stimulus. Both the blastocyst and the corpus luteum then remain quiescent. Thus diapause is maintained by elevated prolactin. Luteal cells have a high concentration of prolactin receptors (Sernia and Tyndale-Biscoe, 1979). Prolactin suppresses activity of the corpus luteum and so prevents secretion of progesterone (Hearn, 1973, Hinds, 1989, Hinds and Tyndale-Biscoe, 1982, Sernia and Tyndale-Biscoe, 1979). Thus prolactin is luteostatic in the tammar, in contrast to the luteotrophic actions of prolactin in other mammalian species, and the absence of a hormonal signal (progesterone) from the quiescent corpus luteum maintains diapause. Interestingly, hypophysectomy will terminate pregnancy because it removes the source of prolactin that maintains the delay (Hearn, 1974, Hearn, 1975), clearly demonstrating the CL can continue its development and function without further stimulation by pituitary gonadotrophins.

The tammar blastocyst remains in diapause under a regimen of low progesterone until either the sucking stimulus is removed or lost, or until the longest day (in the Southern Hemisphere December $\left.21-22^{\text {nd }}\right)$. Diapause therefore normally extends from the post-partum oestrus at the end of January immediately after birth, and is maintained for 11 months.

\section{Reactivation from diapause}

Reactivation from diapause occurs at three levels: the corpus luteum of the ovary, the secretory activity of the endometrium and in the blastocyst itself.
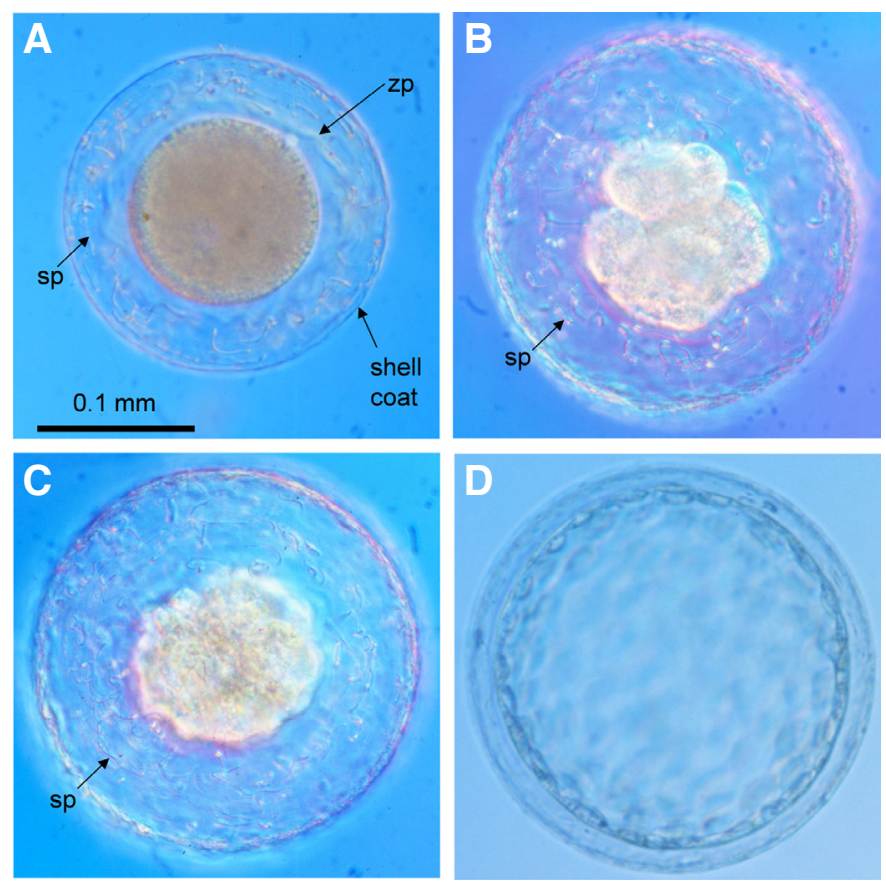

Fig. 1. Representative cleavage stage embryos and blastocyst of the tammar wallaby. (A) Single cell fertilised egg: note the supernumery sperm (sp) trapped in the mucin layer (arrows) and the zona pellucida (zp) surrounding the oocyte. (B) 8 cell embryo. (C) $16+$ cell embryo. All have a thick mucin layer with numerous sperm trapped in it outside the zona. (D) The 80-100 cell blastocyst. Note the lack of any inner cell mass. The blastocyst is unilaminar, and the mucin layer is attenuated. The outer layer is the shell coat. Scale bar, $0.1 \mathrm{~mm}$. 


\section{The ovary}

If the sucking pouch young is removed (RPY=removal of pouch young) prolactin levels decline and both the $C L$ and the blastocyst reactivate. On removal of the sucking stimulus, the luteostatic action of prolactin diminishes, but the sucking stimulus and hence prolactin needs to be absent for at least 3 days (Gordon et al., 1988, Hinds et al., 1992) for the blastocyst to be irrevocably committed to reactivation. Similarly, hypophysectomy (Hearn, 1974, Hearn, 1975) or administration of a dopamine agonist, such as bromocriptine (Tyndale-Biscoe and Hinds, 1984) or cabergoline (Hearn et al., 1998), also suppress prolactin secretion and remove the inhibition on the corpus luteum. Thus the production of progesterone from the corpus lutem is essential for the reactivation after diapause, although the ovaries can be dispensed with from day 8 after RPY (Renfree and Tyndale-Biscoe, 1973, Tyndale-Biscoe, 1970, Young and Renfree, 1979). Indeed, the diapausing tammar embryo can survive many months after ovariectomy or luteectomy (Tyndale-Biscoe and Hearn, 1981). After RPY, there is a pulse of progesterone that occurs on day 4, 56 or 7 after RPY and this coincides exactly with a short pulse of oestrogen (Flint and Renfree, 1982, Hinds and Tyndale-Biscoe, 1982, Shaw and Renfree, 1986, Tyndale-Biscoe et al., 1983). However progesterone alone is all that is needed to induce resumption of active pregnancy to term (Renfree and Tyndale-Biscoe, 1973). Nevertheless, and unlike in mice, progesterone is not needed to maintain the tammar uterus during diapause, and oestradiol alone will not reactivate the blastocyst. In fact, treatment of lactating females with oestradiol either has no effect, or initiates expansion followed by collapse of blastocysts (Fletcher et al., 1988).

\section{The uterus}

Maintenance of the viable blastocyst for 11 months and inhibition of further growth during diapause in the tammar is completely dependent on the uterine environment. During diapause the uterus is relatively inactive with low secretion levels and there are no obvious changes (Renfree, 1973a, Shaw, 1996, Tyndale-Biscoe and Renfree, 1987).

During pregnancy, the uteri of all marsupial species so far described becomes highly secretory (the potoroo, Shaw and Rose, 1979; brushtail possum, Arnold and Shorey, 1985; Shorey and Hughes, 1973; the brown antechinus, Cruz and Selwood, 1993; the stripe-faced dunnart, Cruz and Selwood, 1997, Selwood and Woolley, 1991; and the Virginia opossum, Fleming and Harder, 1981, Padykula and Taylor, 1976). However, the uterine response during pregnancy in the period after embryonic diapause is most extensively described in the tammar (Renfree, 1972, Renfree, 1973a, Renfree and Tyndale-Biscoe, 1973, Shaw, 1996). Distinct changes are detectable in the uterus depending on the phase of the cycle and response to changing levels of steroid hormones in the circulation. During the follicular or proliferative phase of the cycle, when follicles grow and mature in the ovary, there is marked hyperplasia of the uterine epithelium and glands (Clark and Poole, 1967). During the luteal phase of the cycle, after oestrus and ovulation, the uterus becomes secretory with marked hypertrophy of uterine cells as a result of stimulation by progesterone (Clark and Poole, 1967, Shorey and Hughes, 1973, Tyndale-Biscoe and Renfree, 1987, Walker and Hughes, 1981). Ultrastructurally, there is an increase in endometrial activity during early pregnancy reflected by the distribution and abundance of various cellular organelles, together with a marked increase in dilated rough endoplasmic reticulum, Golgi complexes and secretory vesicles in the uterine glands, suggestive of active synthesis and secretion, in mid pregnancy (Freyer et al., 2002). There is structural remodelling that increases sub-epithelial gland density in the endometrial stroma due to both hyperplasia and hypertrophy of glandular cells. The transient rise in progesterone from the corpus luteum induces further uterine secretion from the endometrium, since endometrial weight increases significantly by day 6 after RPY and by day 8 there is a significant increase in the diameter of the blastocyst (Renfree and Tyndale-Biscoe, 1973). The weight of the gravid endometrium is significantly greater than that of the non-gravid side in the same animal, and the composition of uterine secretions also differs between the two sides (Renfree, 1972, Renfree, 1973a, Renfree and Tyndale-Biscoe, 1973). This difference is initially due to the vascular arrangement of the reproductive tract and presence of a single corpus luteum which ensures there is always a higher content of protein in the gravid compared to the non-gravid uterus (Renfree, 1972), and a greater rate of protein synthesis in the gravid uterus (Renfree, 1972, Shaw and Renfree, 1986) because progesterone is preferentially delivered to the gravid uterus (Towers et al., 1986). However, after day 15, differences between the two uteri emerge that are due to the presence of the developing embryo and appear to be the result of stimulation by the placenta or placental hormones demonstrating that there is maternal recognition of pregnancy (Menzies et al., 2011, Renfree, 1972, Renfree, 2000). Thus only the gravid uterus maintains secretory activity as pregnancy progresses (Renfree, 1972, Renfree, 2000, Renfree and Tyndale-Biscoe, 1973, Tyndale-Biscoe and Renfree, 1987, Wallace, 1981).

\section{The blastocyst}

The tammar blastocyst is completely enclosed by three acellular embryonic coats from the time it enters the uterus. The zona pellucida is surrounded by a thick mucin layer (somewhat akin to that of the rabbit) and outside this a shell coat is laid down by the cells around the utero-tubal junction (reviewed in Shaw et al., 1996). The shell coat remains for two-thirds of the active gestation, or 19 days of the 26.5 day gestational period, so early development of the tammar embryo in utero is completely dependent on the secretions of the endometrial glands containing small molecules capable of penetrating these tertiary coats (Renfree and Shaw, 2000, Renfree and Tyndale-Biscoe, 1973, Shaw, 1996).

The tammar blastocyst is a relatively passive partner in early development. The cleavage stages proceed relatively autonomously in the tammar and cleavage can continue in culture (Renfree and Lewis, 1996) (Fig. 1), but to date diapause has never been broken in vitro, even using media conditioned by incubating reactivated endometrium or in co-culture with endometrium (MB Renfree, unpublished data). This may be due partially to the long time taken for reactivation of the corpus luteum and the resumption of progesterone synthesis. During diapause, the blastocyst remains viable and has a low metabolic rate. Glucose uptake during diapause suggests that this rate of metabolism provides sufficient energy for the maintenance and homeostasis of the embryo during the long period of arrest (Spindler, 1997, Spindler et al., 1995, Spindler et al., 1998). The first sign of metabolic change is at day 4 RPY as are the first mitoses are seen in luteal cells and in the blastocyst itself. Thus the blastocyst remains essentially quiescent for the first three days after the trigger for reactivation. 


\section{Growth and transcription factors}

Progesterone and oestradiol induce the production and release of some cytokines and growth factors from the uterus that can have both autocrine and paracrine actions to regulate the pre-implantation embryo and prepare the endometrium for implantation (Sharkey, 1998). These may have an important role to stimulate subsequent resumption of embryonic growth after embryonic diapause (Renfree and Shaw, 2000). Of the known growth factors, leukaemia inhibitory factor (LIF), insulin-like growth factor (IGF), epidermal growth factor (EGF), platelet-derived growth factor (PDGF), fibroblast growth factor (FGF), platelet activating factor (PAF) and transforming growth factor- $\beta$ (TGF- $\beta$ ) are present in the uterus and all have been shown to influence the development and growth of the pre-implantation embryo in eutherian mammals. Some of these have now been examined in the tammar, namely PAF and PAFR, MSX and LIF. A brief description of each of these follows.

\section{PAF and PAF-receptor}

In eutherians, both the phospholipid PAF and its receptor, platelet-activating factor receptor (PAFR) are present in the embryo and the endometrium. PAF may be important for implantation and maternal recognition of pregnancy (O'Neill, 1991) and enhances mitoses in preimplantation embryos in mice (Roberts et al., 1993). Paf generates a pro-survival anti-apoptotic transcriptome within the embryo (Jin and O'Neill, 2011) and maintains the tumour suppressor protein P53 in a latent state (Jin et al., 2009). In the tammar, PAF is present in the culture media after incubation of endometrial explants during embryonic diapause and at all reactivation stages examined (Kojima et al., 1993). Although PAF production was highly variable, its levels appear to increase at reactivation, around four days after removal of the pouch young (RPY) when progesterone secretion from the corpus luteum resumes (Kojima et al., 1993).

The gene for PAFR, PTAFR, is expressed in the tammar endometrium throughout the period of entry into diapause, diapause as well as after reactivation and so does not appear to vary greatly (Fenelon et al., 2014). PAFR protein is also expressed strongly in the apical regions in the plasma membrane of tammar cleavage stage embryos before diapause and has a distinct localised cytoplasmic staining at the eight-cell stage. However, while PAFR protein is only expressed in low levels in the embryo during diapause, on reactivation it is up-regulated and internalised with localised cytoplasmic expression in the perinuclear region, suggesting that endometrial PAF is involved in its reactivation (Fenelon et al., 2014) (Fig. 2). However, although PTAFR mRNA is expressed before, throughout and after diapause, PAFR protein is very low during diapause and so regulation appears to be at the protein level. Further characterisation of the role of this phospholipid in onset and reactivation from diapause in the tammar is awaited with interest.

\section{Muscle segment homeobox gene, MSX}

Muscle segment homeobox (MSX) genes are important for ensuring a receptive uterus and are members of an ancient, highly conserved homeobox gene family (Daikoku et al., 2011). Ablation of both Msx1 and Msx2 in mice uteri prevents implantation by inducing a non-receptive uterus (Nallasamy et al., 2012). In the mouse without diapause, expression is transient at early day 4 . In contrast, during diapause, Msx1 is highly expressed, and in mice with conditional uterine inactivation of Msx1 and Msx2 there is reduced blastocyst recovery and survival (Cha et al., 2013). These mice also fail to achieve true delay, suggesting that the entry into diapause is under maternal control. Oestrogen and progesterone do not directly induce $M s x 1$ but in mice, the effects of Msx genes in diapause are mediated through Wnt5a, a known transcriptional target of uterine Msx (Cha et al., 2013, Nallasamy et al., 2012). Interestingly, Msx1 expression persists in Lif-/ mice but LIF injection induces implantation and downregulation of $M s x 1$ expression (Cha et al., 2013; also see below). Loss of Msx1/Msx2 expression correlates with altered uterine luminal/epithelial cell polarity and affects $E$-cadherin/ $\beta$-catenin complex formation through the control of Wnt5a expression (Daikoku et al., 2011).

The role of MSX genes is highly conserved in mammals and it acts as a molecular mediator in the uterus during embryonic diapause. In the mink, Mustela vison, and tammar wallaby there is a similar expression pattern of MSX1 and MSX2 to that of mice. It persists during diapause and is rapidly downregulated upon blastocyst reactivation and implantation/attachment. However, whilst in mice and mink the predominant gene is $M S X 1$, in the tammar it is MSX2. MSX1 is undetectable in the tammar uterus throughout diapause. It is also virtually undetectable on the day before birth and day of birth, but a few days later MSX2 is highly expressed by $\mathrm{d} 4$ post-partum and remains high during diapause. After reactivation it decreases progressively up to day 5 RPY (Cha et al., 2013). It is interesting that this basic mechanism controlling embryonic diapause has been conserved between mammals of different orders that have been separated for around 160 million years (Luo et al., 2011)(Fig. 2).

\section{Leukaemia inhibitory factor, LIF}

Of the growth factors in the cytokine family, several studies have implicated leukaemia inhibitory factor (LIF) as a potential regulator of early development of the eutherian embryo. Mouse embryos depend on LIF for implantation (Dey et al., 2004, Stewart et al., 1992). LIF binds to a heterodimer of LIF receptor and IL6ST (a.k.a. gp130), and their mRNAs are all expressed in the blastocyst (Nichols et al., 1996). Mouse embryos that are IL6STF survive unimplanted in the uterus after ovariectomy but cannot resume development subsequently once restored to an oestrogen-rich environment specifically because of the loss of an epiblast component (Nichols et al., 2001). As noted above, there is an interaction between Msx 1 and Lif. Implantation failure in Lif mutant mice could be due to sustained expression of Msx1 in the luminal epithelium, but Hoxa10 is correctly expressed in the uterus lacking Lif (Daikoku et al., 2004). There appears to be a positivenegative feedback loop between Msx1 and Lif in regulating each other's activity (Daikoku et al., 2011).

In the mink (Song et al., 1998), Western spotted skunk (Hirzel et al., 1999) and the laboratory mouse (Bhatt et al., 1991) LIF is expressed in the uterus either at very low or undetectable levels during diapause and is dramatically increased with the resumption of development and implantation. This suggests that LIF may have a role in terminating diapause and in subsequent embryonic cell proliferation and differentiation. However, it is not known whether LIF has any effects on diapause in the tammar. There may be a relationship between the persistence of IL6ST/LIFR expression and the duration of diapause (Nichols et al., 2001). Certainly there is some evidence for this in the tammar. We have been measuring the levels of LIFmRNA in the endometrium before, during and after blastocyst reactivation. Oestradiol is released from the Graafian 
follicle and increases to a peak about 12 hours post-partum (Shaw and Renfree, 1986), and at this time LIF is high. LIF then decreases in the endometrium as the oestradiol levels fall and the conceptus enters diapause. This is similar to that observed in the brushtail possum Trichosurus vulpecula in which LIF mRNA transcript is expressed at low levels in the uterus containing an embryo at the single cell or 8-16 cell stage (Cui and Selwood, 2000). LIFexpression is low during the 11 month diapause in the tammar, and increases dramatically after the blastocyst has reactivated (MB Renfree, $\mathrm{H}$ Clark, AJ Pask and G Shaw, unpublished observations) (Fig. 2). However, it is not yet known if this is the initial signal for reactivation or simply accompanies the reactivation of the blastocyst and subsequent embryonic growth.

\section{Other regulatory factors}

There are many other growth factors and cytokines produced by the uterine endometrium that may have a role in the regulation of diapause. Mitotic arrest occurs at the G0 or G1 phase of the cell cycle, possibly mediated by p21 and there is now evidence that there are a number of other factors that are involved in the onset and regulation of diapause (Lopes et al., 2004). PCNA1 induces DNA synthesis and is regulated by p21 (Fotedar et al., 2004). FOXO also induces p21 expression and mitotic arrest so may also play a role in the maintenance of diapause (Lopes et al., 2004). Estrogen is known to stimulate expression of the EGF family, and EGF is a potent mitogen expressed in the uterus during implantation in the mouse (Dey et al., 2004). However, surprisingly expression of p53, a cell cycle inhibitor, does not differ between dormant and active mouse blastocysts (Hamatani et al., 2004). Vascular endothelial growth factor (VEGF) induces endothelial proliferation and vascularisation in the uterus and is upregulated in the mink at reactivation (Lopes et al., 2003, Lopes et al., 2006). In the tammar, VEGF mRNA expression of placental origin certainly increases from mid-pregnancy as does IGF2 (Ager et al., 2008) but levels during diapause and early reactivation are as yet unknown. Polyamines are another interesting group of molecules that indirectly regulate cell cycling and protein synthesis, and there is accumulating evidence that they may play a role in diapause. In the mink, genes that inhibit polyamine degradation are upregulated (Lefevre et al., 2011a, Lefevre et al., 2011b, Fenelon et al., this volume) and the polyamine putrescine and its synthetic enzyme ornithine decarboxylase are expressed at the termination of diapause in the mink (Murphy, 2012). Further study of these and other numerous growth factors and cytokines will provide new evidence for the molecular control of embryonic diapause.

\section{Conclusions}

New understanding of cytokines and growth factors have opened up some surprising new avenues for understanding the role of the uterus in controlling embryonic diapause. The similarity of the patterns of changes in these cytokines in diapause and reactivation, in tammars, mice and mink suggests that, despite the very different endocrine controls of diapause, the endocrine pathways converge on common regulatory pathways in the uterus that regulate early embryo development and diapause. Marsupials diverged from eutherian mammals about 160 million years ago, so these pathways are ancient and conserved, and they probably apply to all mammals, but are activated in only a few. It is possible that all mammals once had diapause (reviewed in
A

B

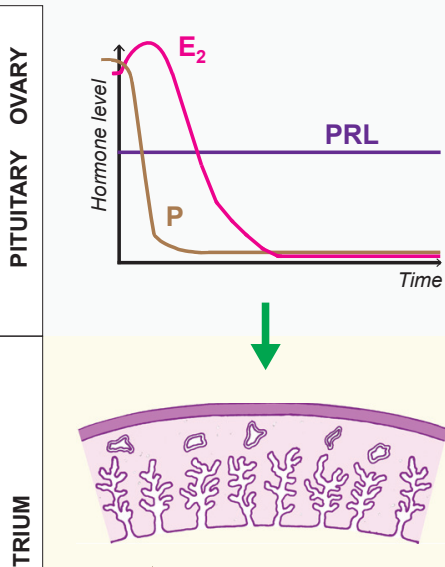

LIF $\uparrow$ MSX

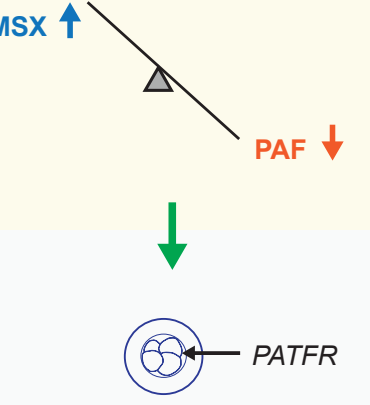

Diapause

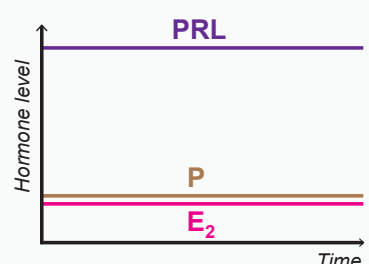

Time

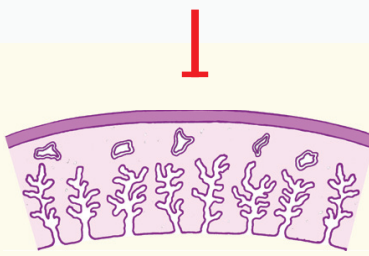

MSX 4

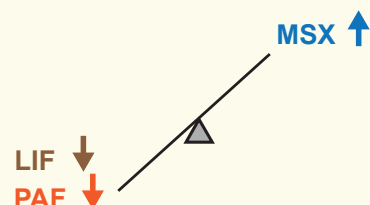

1

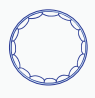

\section{Reactivation}

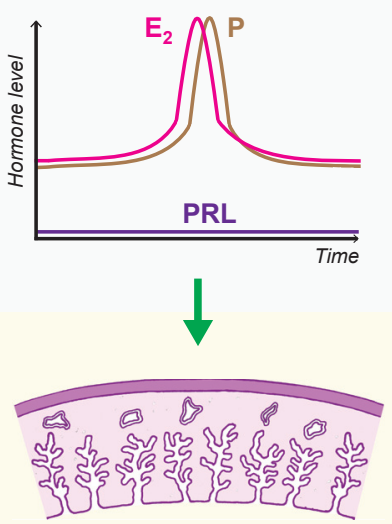

LIF $\uparrow$

PAF $\uparrow$
Fig. 2. Regulators of embryonic diapause in the tammar wallaby. (A) The signals from the pituitary (PRL: prolactin) and ovary ( $P$ : progesterone; $E_{2}$ : estradiol $\left.17 \beta\right)$ determine the secretory activity of the endometrium. (B) Endometrial cytokines, transcription factors and growth factors in the uterine secretions are maintained at differing levels to induce entry into diapause, maintain the quiescent phase of diapause and in reactivation shown by the see-saw relationships between them. LIF: leukaemia inhibitory factor protein; MSX: muscle segment homeobox protein; PAF: Platelet activating factor protein. (C) The inhibitory or stimulatory effects act ultimately on the cleavage stage (left) or blastocyst stage (middle, right) embryos. PATFR: Platelet activation factor receptor gene. Data from references cited in text and unpublished results. 
Fenelon et al., this issue). Where there is a selective advantage for a delay in gestation, any mutations or epigenetic changes that activate these common underlying mechanisms will be positively selected. Conversely where diapause has evolved, there will be selective pressures to lose this trait if it becomes unnecessary through environmental change. Thus the diversity of endocrine controls for diapause may arise because there are potentially many ways to hormonally regulate the ovarian hormone output or alter the uterine responsiveness to ovarian steroids and consequently modulate these basic pathways to control diapause. However, the uterine signals appear to be remarkably conserved.

\section{Acknowledgements}

Much of the work reviewed here was supported by grants to MBR and GS from the Australian Research Council and the National Health and Medical Research Council. We thank our many students and collaborators for their contributions to helping us understand the control of embryonic diapause in the tammar wallaby. We thank Elizabeth Pharo for assistance with the figures.

\section{References}

AGER, E.I., PASK, A.J., SHAW, G. and RENFREE, M.B. (2008). Expression and protein localisation of IGF2 in the marsupial placenta. BMC Dev Biol 8: 17.

ARNOLD, R. and SHOREY, C.D. (1985). Structure of the uterine luminal epithelium of the brush-tailed possum (Trichosurus vulpecula). J Reprod Fertil 74: 565-573.

BHATT, H., BRUNET, L.J. and STEWART, C.L. (1991). Uterine expression of leukemia inhibitory factor coincides with the onset of blastocyst implantation. Proc NatlAcad Sci USA 88: 11408-11412.

CHA, J., SUN, X., BARTOS, A., FENELON, J., LEFEVRE, P., DAIKOKU, T., SHAW, G., MAXSON, R., MURPHY, B.D., RENFREE, M.B. et al., (2013). A new role for muscle segment homeobox genes in mammalian embryonic diapause. Open Biol 3: 130035.

CLARK, M. and POOLE, W. (1967). The reproductive system and embryonic diapause in the female kangaroo, Marcopodus giganteus. Aust $J$ Zool 15: 441-459.

CRUZ, Y.P. and SELWOOD, L. (1993). Uterine histology of the dasyurid marsupial, Antechinus stuartii: relationship with differentiation of the embryo. J Reprod Fertil 99: 237-242.

CRUZ, Y.P. and SELWOOD, L. (1997). Histological differences between gravid and non-gravid uteri in the dasyurid marsupial, Sminthopsis macroura (Spencer). $J$ Reprod Fertil 111: 319-325.

CUI, S. and SELWOOD, L. (2000). cDNA cloning, characterization, expression and recombinant protein production of leukemia inhibitory factor (LIF) from the marsupial, the brushtail possum (Trichosurus vulpecula). Gene 243: 167-178.

DAIKOKU, T., CHA, J., SUN, X., TRANGUCH, S., XIE, H., FUJITA, T., HIROTA, Y., LYDON, J., DEMAYO, F., MAXSON, R. et al., (2011). Conditional deletion of MsX homeobox genes in the uterus inhibits blastocyst implantation by altering uterine receptivity. Dev Cell 21: 1014-1025.

DAIKOKU, T., SONG, H., GUO, Y., RIESEWIJK, A., MOSSELMAN, S., DAS, S.K. and DEY, S.K. (2004). Uterine Msx-1 and Wnt4 signaling becomes aberrant in mice with the loss of leukemia inhibitory factor or Hoxa-10: evidence for a novel cytokine-homeobox-Wnt signaling in implantation. Mol Endocrinol 18: 1238-1250.

DENKER, H.W. and TYNDALE-BISCOE, C.H. (1986). Embryo implantation and proteinase activities in a marsupial (Macropus eugenii). Cell and Tissue Research 246: 279-291.

DEY, S.K., LIM, H., DAS, S.K., REESE, J., PARIA, B.C., DAIKOKU, T. and WANG, H. (2004). Molecular cues to implantation. Endocr Rev 25: 341-373.

FENELON, J.C., BANERJEE, A. and MURPHY, B.D. Embryonic diapause: development on hold. Int $J$ Dev Biol (this issue).

FENELON, J.C., SHAW, G., O'NEILL, C., FRANKENBERG, S. and RENFREE, M.B. (2014). Paf receptor expression in the marsupial embryo and endometrium during embryonic diapause. Reproduction 147: 21-31.

FLEMING, M.W. and HARDER, J.D. (1981). Uterine histology and reproductive cycles in pregnant and non-pregnant opossums, Didelphis virginiana. J Reprod Fertil 63: 21-24.
FLETCHER, T.P., JETTON, A.E. and RENFREE, M.B. (1988). Influence of progesterone and oestradiol-17b on blastocysts of the tammar wallaby (Macropus eugenii) during seasonal diapause. J Reprod Fertil 83: 193-200.

FLINT, A.P. and RENFREE, M.B. (1982). Oestradiol-17b in the blood during seasonal reactivation of the diapausing blastocyst in a wild population of tammar wallabies. J Endocrinol 95: 293-300.

FLINT, A.P.F., RENFREE, M.B. and WEIR, B.J. (1981). Embryonic diapause in mammals. In Journal of Reproduction and Fertility Supplement, (ed., pp. v, 260p, 22 p of plates. Cambridge, Colchester: Journal of Reproduction \& Fertility; Biochemical Society Book Depot.

FOTEDAR, R., BENDJENNAT, M. and FOTEDAR, A. (2004). Functional analysis of CDK inhibitor p21WAF1. Methods Mol Biol 281: 55-71.

FREYER, C., ZELLER, U. and RENFREE, M.B. (2002). Ultrastructure of the placenta of the tammar wallaby, Macropus eugenii: comparison with the grey short-tailed opossum, Monodelphis domestica. J Anat 201: 101-119.

GORDON, K., FLETCHER, T.P. and RENFREE, M.B. (1988). Reactivation of the quiescent corpus luteum and diapausing embryo after temporary removal of the sucking stimulus in the tammar wallaby (Macropus eugenii). J Reprod Fertil 83: 401-406.

HAMATANI, T., DAIKOKU, T., WANG, H., MATSUMOTO, H., CARTER, M.G., KO, M.S. and DEY, S.K. (2004). Global gene expression analysis identifies molecular pathways distinguishing blastocyst dormancy and activation. Proc Natl Acad Sci USA 101: 10326-10331.

HEARN, C.M., SHAW, G., SHORT, R.V. and RENFREE, M.B. (1998). Effects of cabergoline on reproduction in three families of Australian marsupials. J Reprod Fertil 113: 151-157.

HEARN, J.P. (1973). Pituitary inhibition of pregnancy. Nature 241: 207-208.

HEARN, J.P. (1974). The pituitary gland and implantation in the tammar wallaby, Macropus eugenii. J Reprod Fertil 39: 235-241.

HEARN, J.P. (1975). Hypophysectomy of the tammar wallaby, Macropus eugenii: surgical approach and general effects. J Endocrinol 64: 403-416.

HINDS, L.A. (1989). Morning pulse of prolactin maintains seasonal quiescence in the tammar, Macropus eugenii. J Reprod Fertil 87: 735-474.

HINDS, L.A., DIGGLE, P.J. and TYNDALE-BISCOE, C.H. (1992). Effects of the ovary, sucking stimulus and season on the pattern of $\mathrm{LH}$ and $\mathrm{FSH}$ release in the female tammar, Macropus eugenii. Reprod Fertil Dev 4: 25-34.

HINDS, L.A. and TYNDALE-BISCOE, C.H. (1982). Plasma progesterone levels in the pregnant and non-pregnant tammar, Macropus eugenii. J Endocrinol93: 99-107.

HIRZEL, D.J., WANG, J., DAS, S.K., DEY, S.K. and MEAD, R.A. (1999). Changes in uterine expression of leukemia inhibitory factor during pregnancy in the Western spotted skunk. Biol Reprod 60: 484-492.

INGRAM, J.N., SHAW, G. and RENFREE, M.B. (1999). Cortisol in fetal fluids and the fetal adrenal at parturition in the tammar wallaby (Macropus eugenii). Biol Reprod 60: 651-655.

JIN, X.L., CHANDRAKANTHAN, V., MORGAN, H.D. and O'NEILL, C. (2009). Preimplantation embryo development in the mouse requires the latency of TRP53 expression, which is induced by a ligand-activated PI3 kinase/AKT/MDM2-mediated signaling pathway. Biol Reprod 81: 234-242

JIN, X.L. and O'NEILL, C. (2011). Regulation of the expression of proto-oncogenes by autocrine embryotropins in the early mouse embryo. Biol Reprod 84: 1216-1224.

KOJIMA, T., HINDS, L.A., MULLER, W.J., O'NEILL, C. and TYNDALE-BISCOE, C.H. (1993). Production and secretion of progesterone in vitro and presence of platelet activating factor (PAF) in early pregnancy of the marsupial, Macropus eugenii. Reprod Fertil Dev 5: 15-25.

LEFEVRE, P.L., PALIN, M.F., CHEN, G., TURECKI, G. and MURPHY, B.D. (2011a) Polyamines are implicated in the emergence of the embryo from obligate diapause. Endocrinology 152: 1627-1639.

LEFEVRE, P.L., PALIN, M.F. and MURPHY, B.D. (2011b). Polyamines on the reproductive landscape. Endocr Rev 32: 694-712.

LOPES, F.L., DESMARAIS, J., GEVRY, N.Y., LEDOUX, S. and MURPHY, B.D. (2003). Expression of vascular endothelial growth factor isoforms and receptors Flt-1 and KDR during the peri-implantation period in the mink, Mustela vison. Biol Reprod 68: 1926-1933.

LOPES, F.L., DESMARAIS, J., LEDOUX, S., GEVRY, N.Y., LEFEVRE, P. and MURPHY, B.D. (2006). Transcriptional regulation of uterine vascular endothelia growth factor during early gestation in a carnivore model, Mustela vison. J Biol Chem 281: 24602-24611. 
LOPES, F.L., DESMARAIS, J.A. and MURPHY, B.D. (2004). Embryonic diapause and its regulation. Reproduction 128: 669-678.

LUO, Z.X., YUAN, C.X., MENG, Q.J. and JI, Q. (2011). A Jurassic eutherian mammal and divergence of marsupials and placentals. Nature 476: 442-445.

MCLAREN, A. (1982). The embryo. In Reproduction in Mammals. Book 2 Embryonic and Fetal Development, (ed. AUSTIN, C. R. and SHORT, R. V.). Cambridge University Press, Cambridge, pp.1-25.

MENZIES, B.R., PASK, A.J. and RENFREE, M.B. (2011). Placental expression of pituitary hormones is an ancestral feature of therian mammals. Evodevo 2: 16.

MURPHY, B.D. (2012). Embryonic diapause: advances in understanding the enigma of seasonal delayed implantation. Reprod Domest Anim 47 Suppl 6: 121-124.

NALLASAMY, S., LI, Q., BAGCHI, M.K. and BAGCHI, I.C. (2012). Msx homeobox genes critically regulate embryo implantation by controlling paracrine signaling between uterine stroma and epithelium. PLoS Genet 8: e1002500.

NICHOLS, J., CHAMBERS, I., TAGA, T. and SMITH, A. (2001). Physiological rationale for responsiveness of mouse embryonic stem cells to gp130 cytokines. Development 128: 2333-2339

NICHOLS, J., DAVIDSON, D., TAGA, T., YOSHIDA, K., CHAMBERS, I. and SMITH, A. (1996). Complementary tissue-specific expression of LIF and LIF-receptor mRNAs in early mouse embryogenesis. Mech Dev 57: 123-131.

O'NEILL, C. (1991). A physiological role for PAF in the stimulation of mammalian embryonic development. Trends Pharmacol Sci 12: 82-84.

PADYKULA, H.A. and TAYLOR, J.M. (1976). Cellular mechanisms involved in cyclic stromal renewal of the uterus. I. The opossum, Didelphis virginiana. Anat Rec 184: 5-25.

PARRY, L.J., GUYMER, F.J., FLETCHER, T.P. and RENFREE, M.B. (1996). Release of an oxytocic peptide at parturition in the marsupial, Macropus eugenii. J Reprod Fertil 107: 191-198.

RENFREE, M.B. (1972). Influence of the embryo on the marsupial uterus. Nature 240: $475-477$.

RENFREE, M.B. (1973a). The composition of fetal fluids of the marsupial Macropus eugenii. Dev Biol 33: 62-79.

RENFREE, M.B. (1973b). Proteins in the uterine secretions of the marsupial Macropus eugenii. Dev Biol 32: 41-49.

RENFREE, M.B. (1981). Embryonic diapause in marsupials. J Reprod Fertil Suppl 29: 67-78.

RENFREE, M.B. (1994). Endocrinology of pregnancy, parturition and lactation in marsupials. In Marshall's Physiology of Reproduction, vol. 3: Pregnancy and Lactation (ed. LAMMING, G. E.). Chapman \& Hall, London, UK, pp. 677-766.

RENFREE, M.B. (2000). Maternal recognition of pregnancy in marsupials. Rev Reprod 5: 6-11.

RENFREE, M.B. and CALABY, J.H. (1981). Background to delayed implantation and embryonic diapause. J Reprod Fertil Suppl 29.

RENFREE, M.B. and LEWIS, A.M. (1996). Cleavage in vivo and in vitro in the Marsupial Macropus eugenii. Reprod Fertil Dev 8: 725-742.

RENFREE, M.B. and SHAW, G. (2000). Diapause. Ann. Rev. Physiol. 62: 353-375.

RENFREE, M.B., SHAW, G. and FLETCHER, T.P. (1994). Evidence for the essential role of prostaglandins for parturition in a marsupial, Macropus eugenii. $J$ Reprod Fertil 102: 433-446.

RENFREE, M.B. and TYNDALE-BISCOE, C.H. (1973). Intrauterine development after diapause in the marsupial Macropus eugenii. Dev Biol 32: 28-40.

ROBERTS, C., O'NEILL, C. and WRIGHT, L. (1993). Platelet activating factor (PAF) enhances mitosis in preimplantation mouse embryos. Reprod Fertil Dev5:271-279.

RUDD, C.D. (1994). Sexual behaviour of male and female tammar wallabies (Macropus eugenii) at post-partum oestrus. J. Zoology 232: 151-162.

SELWOOD, L. and WOOLLEY, P.A. (1991). A timetable of embryonic development, and ovarian and uterine changes during pregnancy, in the stripe-faced dunnart, Sminthopsis macroura (Marsupialia: Dasyuridae). J Reprod Fertil 91: 213-227.

SERNIA, C. and TYNDALE-BISCOE, C.H. (1979). Prolactin receptors in the mammary gland, corpus luteum and other tissues of the tammar wallaby, Macropus eugenii. J Endocrinol 83: 79-89.

SHARKEY, A. (1998). Cytokines and implantation. Rev Reprod 3: 52-61.

SHAW, G. (1996). The uterine environment in early pregnancy in the tammar wallaby. Reprod Fertil Dev 8: 811-818.
SHAW, G. and RENFREE, M.B. (1984). Concentrations of oestradiol-17 beta in plasma and corpora lutea throughout pregnancy in the tammar, Macropus eugenii. $J$ Reprod Fertil 72: 29-37.

SHAW, G. and RENFREE, M.B. (1986). Uterine and embryonic metabolism after diapause in the tammar wallaby, Macropus eugenii. J Reprod Fertil 76: 339-347.

SHAW, G. and RENFREE, M.B. (2001). Fetal control of parturition in marsupials. Reprod Fertil Dev 13: 653-659.

SHAW, G. and RENFREE, M.B. (2006). Parturition and perfect prematurity: birth in marsupials. Aust $J$ Zool 54: 139-149.

SHAW, G., RENFREE, M.B. and FLETCHER, T.P. (1996). A role for glucocorticoids in parturition in a marsupial, Macropus eugenii. Biol Reprod 54: 728-733.

SHAW, G. and ROSE, R. (1979). Delayed gestation in the Potoroo Potorous tridactylus (Kerr). Aust J Zool 27: 901-912.

SHOREY, C.D. and HUGHES, R.L. (1973). Cyclical changes in the uterine endometrium and peripheral plasma concentrations of progesterone in the marsupial Trichosurus vulpecula. Aust J Zool 21: 1-19.

SMITH, M.J. (1981). Morphological observations on the diapausing blastocyst of some macropodid marsupials. J Reprod Fertil 61: 483-486.

SONG, J.H., HOUDE, A. and MURPHY, B.D. (1998). Cloning of leukemia inhibitory factor (LIF) and its expression in the uterus during embryonic diapause and implantation in the mink (Mustela vison). Mol Reprod Dev 51: 13-21.

SPINDLER, R.E. (1997). The metabolism and control of blastocysts during diapause and reactivation in the Tammar wallaby (Macropus eugenii). Thesis (Ph.D.) University of Melbourne, Dept. of Zoology, 1997.

SPINDLER, R.E., RENFREE, M.B. and GARDNER, D.K. (1995). Metabolic assessment of wallaby blastocysts during embryonic diapause and subsequent reactivation Reprod Fertil Dev 7: 1157-1162.

SPINDLER, R.E., RENFREE, M.B., SHAW, G. and GARDNER, D.K. (1998). Reactivating tammar wallaby blastocysts oxidize glucose. Biol Reprod 58: 1425-1431.

STEWART, C.L., KASPAR, P., BRUNET, L.J., BHATT, H., GADI, I., KONTGEN, F. and ABBONDANZO, S.J. (1992). Blastocyst implantation depends on maternal expression of leukaemia inhibitory factor. Nature 359: 76-79.

TOWERS, P.A., SHAW, G. and RENFREE, M.B. (1986). Urogenital vasculature and local steroid concentrations in the uterine branch of the ovarian vein of the female tammar wallaby (Macropus eugenii). J Reprod Fertil 78: 37-47.

TYNDALE-BISCOE, C.H. (1970). Resumption of development by quiescent blastocysts transferred to primed, ovariectomized recipients in the marsupial, Macropus eugenii. J Reprod Fertil 23: 25-32.

TYNDALE-BISCOE, C.H. (1979). Hormonal control of embryonic diapause and reactivation in the tammar wallaby. In Maternal Recognition of Pregnancy. Ciba Found. Symp. 64, (ed. CARSON, D. D.). Excerpta Medica, Amsterdam, pp.173-90.

TYNDALE-BISCOE, C.H. and HEARN, J.P. (1981). Pituitary and ovarian factors associated with seasonal quiescence of the tammar wallaby, Macropus eugenii. $J$ Reprod Fertil 63: 225-230.

TYNDALE-BISCOE, C.H. and HINDS, L.A. (1984). Seasonal patterns of circulating progesterone and prolactin and response to bromocriptine in the female tammar Macropus eugenii. Gen Comp Endocrinol 53: 58-68.

TYNDALE-BISCOE, C.H., HINDS, L.A., HORN, C.A. and JENKIN, G. (1983). Hormona changes at oestrus, parturition and post-partum oestrus in the tammar wallaby (Macropus eugenii). J Endocrinol 96: 155-161.

TYNDALE-BISCOE, H. and RENFREE, M.B. (1987). Reproductive Physiology of Marsupials. Cambridge University Press, Cambridge; Melbourne; New York.

WALKER, M.T. and HUGHES, R.L. (1981). Ultrastructural changes after diapause in the uterine glands, corpus luteum and blastocyst of the red-necked wallaby, Macropus rufogriseus banksianus. J Reprod Fertil Suppl 29: 151-158.

WALLACE, G.I. (1981). Uterine factors and delayed implantation in macropodid marsupials. In Journal of Reproduction and Fertility Supplement, (ed. FLINT, A. P. F., RENFREE, M. B. and WEIR, B. J.). Journal of Reproduction \& Fertility; Biochemical Society Book Depot, Cambridge, Colchester, pp.173-181.

WARD, S.J. and RENFREE, M.B. (1988). Reproduction in females of the feathertail gliders, Acrobates pygmeaus (Marsupialia). J. Zool. (Lond). 216: 225-240.

YOUNG, I.R. and RENFREE, M.B. (1979). The effects of corpus luteum removal during gestation on parturition in the tammar wallaby (Macorpus eugenii). $J$ Reprod Fertil 56: 249-254. 


\section{Further Related Reading, published previously in the Int. J. Dev. Biol.}

Implantation: molecular basis of embryo-uterine dialogue.

B C Paria, H Song and S K Dey

Int. J. Dev. Biol. (2001) 45: 597-605

Endometrial responses to embryonic signals in the primate

Prajna Banerjee and Asgerally T. Fazleabas

Int. J. Dev. Biol. (2010) 54: 295-302

Local regulation of implantation at the human fetal-maternal interface

Evdokia Dimitriadis, Guiying Nie, Natalie J. Hannan, Premila Paiva and Lois A. Salamonsen

Int. J. Dev. Biol. (2010) 54: 313-322

Culture of human preimplantation embryos to the blastocyst stage: a comparison of 3 media.

J Conaghan, K Hardy, H J Leese, R M Winston and A H Handyside

Int. J. Dev. Biol. (1998) 42: 885-893

Reflections on the culture of the preimplantation embryo.

J D Biggers

Int. J. Dev. Biol. (1998) 42: 879-884

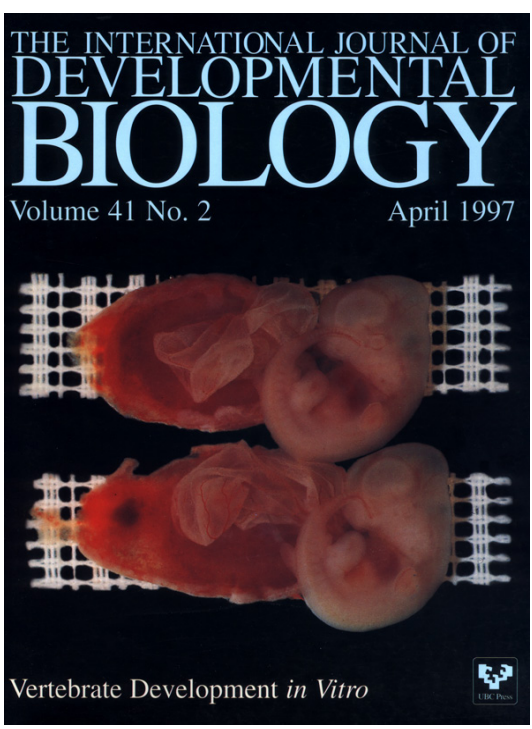

5 yr ISI Impact Factor $(2011)=2.959$
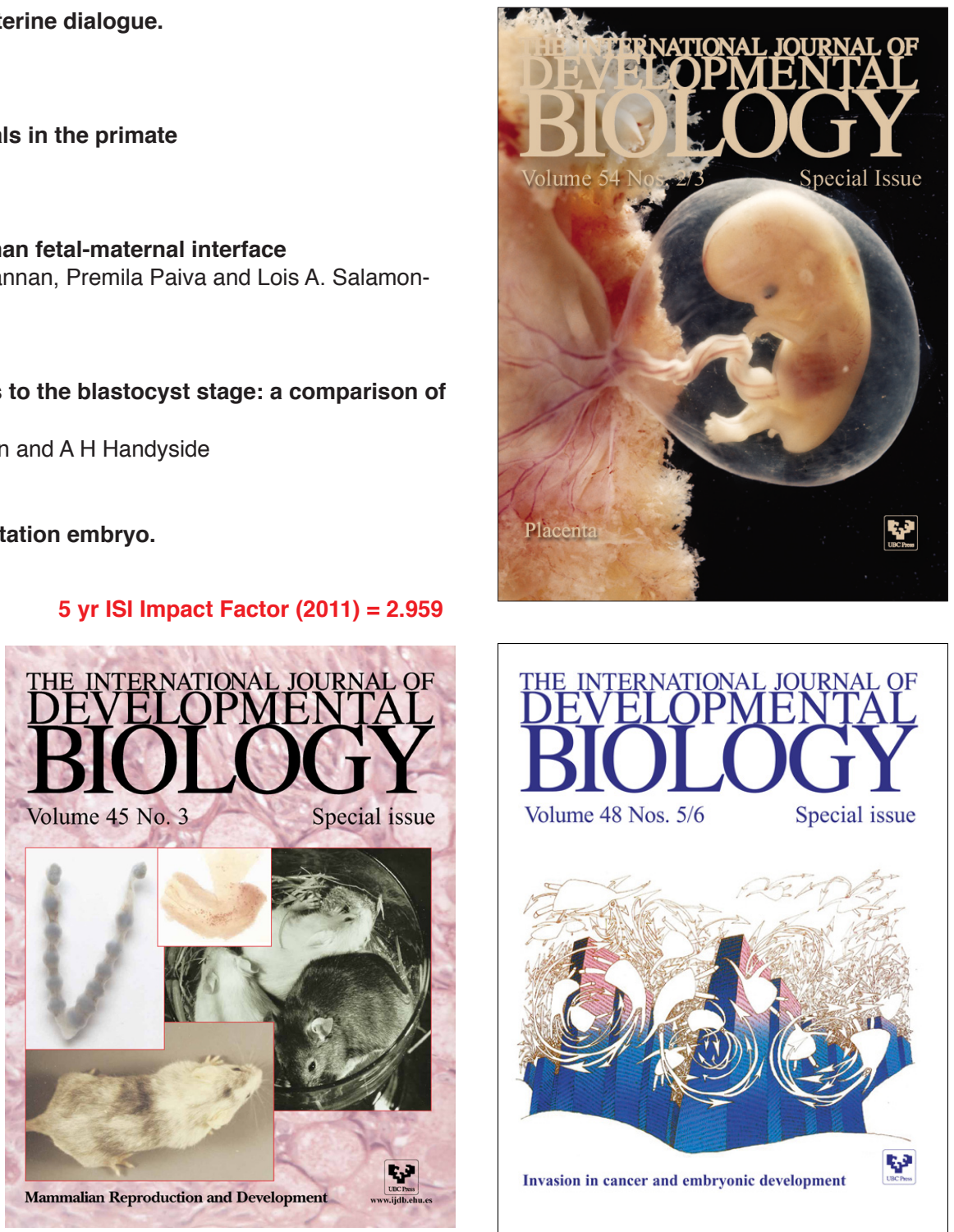

Volume 48 Nos. 5/6

Special issue

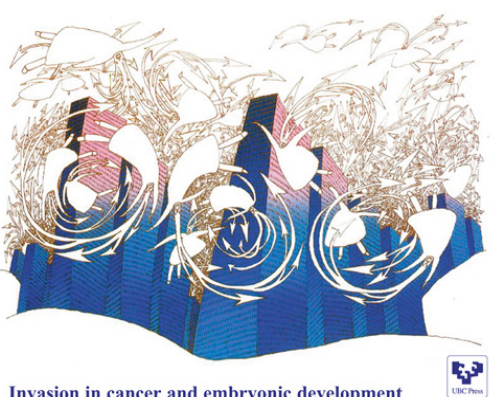

Invasion in cancer and embryonic development

5ives 